\title{
Shading during the grain filling period increases 2-acetyl-1-pyrroline content in fragrant rice
}

\author{
Zhaowen $\mathrm{Mo}^{1,2 \dagger}$, Wu Li ${ }^{3 \dagger}$, Shenggang Pan ${ }^{1,2}$, Timothy L Fitzgerald ${ }^{4}$, Feng Xiao ${ }^{1}$, Yongjian Tang ${ }^{1}$, Yilei Wang ${ }^{1}$, \\ Meiyang Duan ${ }^{1,2}$, Hua Tian ${ }^{1,2}$ and Xiangru Tang ${ }^{1,2^{*}}$
}

\begin{abstract}
Background: Fragrant rice, including Thai jasmine and Indian basmati varieties, is highly valued by consumers globally. 2-acetyl-1-proline (2-AP) is the major compound responsible for the aromatic character of fragrant rice. Previously, environmental factors such as water management and salinity have been proven to influence 2-AP levels in fragrant rice; assessing the effect of additional environmental factors on 2-AP concentration is therefore eminent. The level of solar radiation (solar intensity; SI) to which a crop is exposed can affect growth, yield and grain quality, and other photosynthetic and physiological characteristics. In this study the effect of shading (i.e. the reduction of SI) on yield, quality, and 2-AP concentration in two elite Chinese fragrant rice varieties, 'Yuxiangyouzhan' and 'Nongxiang 18', has been investigated. Furthermore, accumulation of the plant stress response molecules proline and gamma-aminobutyric acid, which have also been implicated in pathways leading to 2-AP production, was assessed to study shading effects on these compounds in fragrant rice, and to further possibly determine fluxes in biochemical pathways leading to 2-AP accumulation.

Results: This study has revealed significant changes in the yield and quality characters under shading treatment. Additionally, 2-AP and GABA content in grains was significantly increased for all shading treatments in both varieties. In addition to 2-AP, ten other volatile compounds were studied; results indicated that shading treatments could have a selective effect on the metabolism of these volatile compounds.

Conclusions: In this study, we have demonstrated that shading during grain filling has significant effects on yield and quality traits in rice, and leads to the accumulation of GABA and 2-AP. We discuss the implications of these findings in terms of pathways leading to 2-AP and GABA production in fragrant rice, which have not been fully elucidated. The shading effect on ten additional volatile compounds is also discussed. Finally we discuss possible effects of variation in solar intensity resulting from anthropogenic emissions on fragrant rice production.
\end{abstract}

Keywords: 2-acetyl-1-pyrroline; Aromatic rice; Y-aminobutyric acid; Proline; Shading treatment; Yield

\section{Background}

Fragrant rice varieties possess a characteristic aroma that is often described as 'nutty' or 'popcorn-like' (Bryant and McClung, 2010). Thai 'jasmine' and indian 'basmati' are the most widely-recognized types of fragrant rice. Fragrant rice is highly desired by consumers and attracts premium price in many markets (Sakthivel et al., 2009);

\footnotetext{
* Correspondence: tangxr@scau.edu.cn

${ }^{\dagger}$ Equal contributors

'College of Agriculture, South China Agricultural University, Guangzhou, Guangdong, 510642, China

${ }^{2}$ Scientific Observing and Experimental Station of Crop Cultivation in South China, Ministry of Agriculture. P. R. China, Guangzhou, Guangdong 510642, China

Full list of author information is available at the end of the article
}

furthermore, global demand for fragrant rice is increasing (Hashemi et al., 2013).

The volatile compounds in rice are complicated; instrumental analyses have observed more than 200 volatile compounds (Tsugita, 1985;Buttery et al., 1988; Champagne, 2008). Buttery et al. (1988) demonstrated that the probable key contributors to cooked rice aroma among the detected compounds were 2acetyl-l-pyrroline, (E,E)-2,4-decadienal, nonanal, hexanal, (E)-2-nonenal, octanal, decanal, 4-vinyl-guaiacol, and 4-vinylphenol. Jezussek et al. (2002) suggested that 2-amino acetophenone and 4,5-epoxy-(E)-2-decenal were important previously unknown rice aroma compounds. Maraval et al. (2008) indicated that 
organic extracts of cooked aromatic rice showed similar aroma profile between the cultivars, but showed substantial differences in the levels of various volatile compounds. Moreover, Yang et al. (2008) suggested that 13 volatile coupounds may contribute to differences in aroma.

Despite the complexity of volatile compounds in rice (Champagne et al., 2005), a single volatile compound, 2-acetyl-1-pyrroline (2-AP), is well-proven to be primarily responsible for the aromatic character of fragrant rice (Buttery et al., 1983, 1986; Widjaja et al., 1996; Jezussek et al., 2002). In fragrant rice, 2-AP can be detected in all parts of the plant except the roots (Buttery et al., 1983; Maraval et al., 2010); 2-AP is also present in non-fragrant rice varieties, but at much lower concentration (Widjaja et al., 1996).

The inactivation of $B A D H 2$, encoding an aminoaldehyde dehydrogenase, is responsible for the accumulation of 2-AP in fragrant rice varieties (Bradbury et al., 2005; Bradbury et al., 2008). Proline is a precursor of 2-AP in rice (Yoshihashi et al., 2002), and $\gamma$-aminobutyraldehyde (GABald) is likely to be the direct precursor to 2-AP production via $B A D H 2$; Bradbury et al. (2008) proposed that functional $B A D H 2$ catalyses the conversion of GABald to $\gamma$-aminobutyric acid (GABA), while non-functional $B A D H 2$ in fragrant rice leads to cyclisation of GABald to $\Delta^{1}$-pyrroline, with the addition of an acetyl group forming 2-AP. The role of proline in plant stress tolerance is well-established (Szabados and Savouré, 2010); additionally, GABA accumulates in response to biotic and abiotic stresses in plants (Bouche and Fromm, 2004) and is therefore speculated to play a role in stress tolerance (Kinnersley and Turano, 2000). Thus, it appears that there is an overlap in pathways involved in 2-AP accumulation and the response to stress. In further support of an interaction between 2-AP production and stress responses, environmental factors have been observed to influence the level of 2-AP in fragrant rice grains. For example, Yoshihashi et al. (2002) reported that drought stress during grain formation increased 2-AP content, and Gay et al. (2010) and Poonlaphdecha et al. (2012) have also recently reported an increase in 2-AP accumulation in response to salt stress. Interestingly, elite fragrant rice varieties are relatively susceptible to abiotic and biotic stresses (Niu et al., 2008), and recently an association of the fragrance phenotype with salt susceptibility has also been reported (Fitzgerald et al., 2010; Wijerathna et al., 2014).

'Photosynthetically Active Radiation' (PAR) is the range of electromagnetic radiation between 400 and 700 nanometers, roughly equivalent to the visible light spectrum, that plants (and most photosynthetic organisms) harness for photosynthesis. The level of PAR to which a plant is exposed is related to photosynthetic rate (McCree, 1981), and variation in PAR can therefore have a major effect on plant growth and development. In the field, the intensity of solar radiation (solar intensity; SI) determines the level of PAR to which a crop is exposed, and variation in solar radiation can affect crop yield (Liu and Tollenaar, 2009). Season, geographic location, and cloud cover are key factors influencing SI; additionally, SI varies in response to atmospheric pollution and water vapour content (Jáuregui and Luyando, 1999; Haywood et al., 2011). The level of SI to which a plant is exposed can also be strongly affected by surrounding vegetation; 'shading stress' in plants growing beneath or amongst a canopy, and responses to such stress, are well-recognised phenomena (Gommers et al., 2013).

To understand how rice responds to low light environment, researchers have used artificial shading to control light density. Studies have showed that shading can affect rice morphological characteristics, physiological characteristics, yield, and quality. For example, Tang (1988) found that shading affected growth and yield, decreased dry matter, and increased leaf thickness. Cai and Luo (1999) reported that shading at different stages decreased rice yield, accumulation rate of dry matter and the uptake of nutrients, but increased nutrient content. Ren et al. (2003) indicated that the distribution and transformation of plant dry matter is affected by shading, and some shading levels decreased rice yield. Besides, Deng et al. (2009) found that the filled grain percentage and yield were obviously affected by shading. Moreover, Liu et al. (2012) reported that the effect of shading on the content of malondialdehyde, souble sugar, souble protein, and protective enzymes activities in leaves various in genotype. Ding et al. (2004) found that shading after heading extended rice growth duration of the flag leaf, decreased decomposing rate of chlorophyll and MDA content, reduced the photosynthesis of the flag leaf, and that the degree of the grainfilling was lower than that of under the strong light. Zhang et al. (2007) indicated that shading affected rice quality differently amongst genotypes, however shading increased protein content and chalkiness and decreased amylose content of all rice cultivars. Liu et al. (2008) found that weak light during grain filling affected rice yield, physiological characteristics and quality, particularly the rate of chalky grains. Additionally, shading has been demonstrated to effect starch synthase and related enzyme activities (Wang et al., 2013).

Previous studies have assessed the effects of an artificial shading (which results in a decrease in SI and PAR) on growth and development, yield, and grain quality in rice (e.g. Tanaka and Kawano, 1966; Cai and Luo, 1999; Ren et al., 2003; Zhang et al., 2007). Here we have studied the impact of shading during the grain filling period on GABA, proline, and 2-AP accumulation in fragrant rice. Furthermore, to provide additional insight into the 
effect of shading on growth and yield in fragrant rice, we have complemented our analyses of metabolite accumulation with assessment of total nitrogen levels, and grain yield and quality in response to shading treatment.

\section{Results}

Effect of shading treatment on yield, yield related traits, dry weight, and harvest index

For Yuxiangyouzhan, all shading treatments resulted in a significant reduction in filled grain percentage, 1000grain weight, grain yield, total dry weight, and harvest index. Additionally, shading treatment during the whole grain filling period (S1) and during the latter stage of grain filling (S3) caused a significant reduction of panicle number. For Nongxiang 18, shading treatment during the whole grain filling stage S1 and during early grain filling (S2) caused a significant reduction of filled grain percentage and 1000-grain weight; and S1 significantly decreased grain yield and total dry weight (Table 1). On average, Yuxiangyouzhan had lower panicles number, filled grain percentage, 1000-grain weight, and total dry weight, but had a higher number of grains per panicle, grain yield, and harvest index than Nongxiang 18 (Table 1).

\section{Effect of shading treatment on grain quality}

Significant effects were identified for some shading treatments on most quality traits. All shading treatments significantly increased grain protein content in both Yuxiangyouzhan and Nongxiang 18 (Table 2). Additionally, a similar effect of shading on chalkiness characterstics was observed in both cultivars; shading during the whole grain filling period and during late grain filling resulted in a decrease in mean rate of chalky grains, and mean degree of chalkiness, however shading during early grain filling significantly increased chalkiness characteristics (Table 2). No significant effect on brown rice rate was detected in the shading treatments for either cultivar, while for milled rice rate, head rice rate and alkali spreading value effects varied with timing, during shading as well as cultivar (Table 2).

\section{Effect of shading treatment on 2-acetyl-1-pyrroline, GABA,} proline, and total nitrogen levels

The 2-AP content in grains was significantly increased for all shading treatments in both varieties, with increases of $59.07-106.65 \%$, and $11.89-42.37 \%$ detected for Yuxiangyouzhan and Nongxiang 18, respectively. In both varieties, the highest mean 2-AP content in grains was identified for plants exposed to S2 treatment, with 2-AP contents of $175.86 \mu \mathrm{g} \cdot \mathrm{kg}^{-1}$ in Yuxiangyouzhan and $135.02 \mu \mathrm{g} \cdot \mathrm{kg}^{-1}$ in Nongxiang 18 , compared to respective means of 85.10 and $94.84 \mu \mathrm{g} \cdot \mathrm{kg}^{-1}$ in the absence of shading (S0) (Figure 1). All shading treatments also significantly increased GABA in the grains of Yuxiangyouzhan (23.59 - 31.01\% ) and Nongxiang 18 (56.99 - 94.18\%) (Figure 2). In Yuxiangyouzhan, a significant increase in proline content was identified for S1 and S2, but not for S3 (Figure 3). For Nongxiang 18, proline content was not significantly affected by any shading treatment (Figure 3). No significant difference in total nitrogen content in grains between shading treatments was observed (Figure 4).

Relationships among 2-Acetyl-1-pyrroline, GABA, proline, and total nitrogen

Significant correlations were identified between 2-AP and GABA in response to shading for Yuxiangyouzhan but

Table 1 Effect of shading treatment on yield, yield related traits, total dry weight, and harvest index

\begin{tabular}{|c|c|c|c|c|c|c|c|}
\hline Treatment & $\begin{array}{c}\text { Panicles } \\
\text { number }\left(\mathrm{m}^{2}\right)\end{array}$ & $\begin{array}{l}\text { Grains per } \\
\text { panicle }\end{array}$ & $\begin{array}{c}\text { Filled grain } \\
\text { percentage }(\%)\end{array}$ & $\begin{array}{l}\text { 1000-grain } \\
\text { weight (g) }\end{array}$ & $\begin{array}{c}\text { Grain } \\
\text { yield }\left(g \cdot \mathrm{m}^{-2}\right)\end{array}$ & $\begin{array}{c}\text { Total dry } \\
\text { weight }\left(g \cdot \mathrm{m}^{-2}\right)\end{array}$ & $\begin{array}{c}\text { Harvest } \\
\text { index (\%) }\end{array}$ \\
\hline \multicolumn{8}{|c|}{ Yuxiangyouzhan } \\
\hline SO & $263.33 \mathrm{a}$ & $185.09 \mathrm{a}$ & 84.48 a & $21.27 \mathrm{a}$ & $863.14 \mathrm{a}$ & $1611.0 \mathrm{a}$ & $53.613 a$ \\
\hline $\mathrm{S} 1$ & $190.00 \mathrm{C}$ & $162.63 \mathrm{a}$ & $51.61 \mathrm{C}$ & $19.51 \mathrm{~b}$ & $494.04 \mathrm{C}$ & $1021.0 \mathrm{C}$ & $48.311 b$ \\
\hline $\mathrm{S} 2$ & $250.00 \mathrm{ab}$ & $165.47 \mathrm{a}$ & $63.38 \mathrm{~b}$ & $19.58 \mathrm{~b}$ & $660.66 \mathrm{~b}$ & $1328.5 \mathrm{~b}$ & $49.602 \mathrm{~b}$ \\
\hline S3 & $218.33 b c$ & $179.61 \mathrm{a}$ & $64.74 \mathrm{~b}$ & $20.04 \mathrm{~b}$ & $523.69 \mathrm{C}$ & $1100.4 \mathrm{C}$ & $47.512 \mathrm{~b}$ \\
\hline mean & 230.42 & $173.20^{*}$ & 66.05 & 20.10 & 635.38 & 1265.2 & $49.759^{*}$ \\
\hline \multicolumn{8}{|l|}{ Nongxiang 18} \\
\hline SO & $284.42 \mathrm{a}$ & $148.41 \mathrm{a}$ & 85.61 a & 25.46 a & $655.19 a$ & 1453.8 a & 44.783 a \\
\hline $\mathrm{S} 1$ & $261.67 \mathrm{a}$ & $126.64 \mathrm{a}$ & $53.32 \mathrm{C}$ & $22.94 b$ & $457.25 \mathrm{~b}$ & 1100.4 b & $41.495 \mathrm{a}$ \\
\hline $\mathrm{S} 2$ & 290.00 a & 129.09 a & $66.01 \mathrm{~b}$ & $23.07 \mathrm{~b}$ & 639.96 a & 1394.9 a & 45.841 a \\
\hline S3 & $273.33 \mathrm{a}$ & 148.32 a & 81.76 a & $24.84 \mathrm{a}$ & 638.35 a & $1376.3 \mathrm{a}$ & $46.084 a$ \\
\hline mean & $277.35^{*}$ & 138.11 & 71.68 & $24.08^{*}$ & 597.68 & 1331.4 & 44.551 \\
\hline
\end{tabular}

Means in the same column followed by different lower case letters for the same variety differ significantly at $P=0.05$ by LSD tests. Means of the two varieties followed by asterisk for the same detected index difer significant at $P=0.05$ by LSD tests. 
Table 2 Effect of shading treatment on grain quality

\begin{tabular}{|c|c|c|c|c|c|c|c|c|}
\hline Treatment & $\begin{array}{l}\text { Brown rice } \\
\text { rate }(\%)\end{array}$ & $\begin{array}{l}\text { Milled rice } \\
\text { rate (\%) }\end{array}$ & $\begin{array}{l}\text { Head rice } \\
\text { rate(\%) }\end{array}$ & $\begin{array}{c}\text { Protein } \\
\text { content(\%) }\end{array}$ & $\begin{array}{l}\text { Amylose } \\
\text { content(\%) }\end{array}$ & Alkali & $\begin{array}{l}\text { grains with } \\
\text { chalkiness (\%) }\end{array}$ & $\begin{array}{l}\text { Chalkiness } \\
\text { degree }(\%)\end{array}$ \\
\hline \multicolumn{9}{|c|}{ Yuxiangyouzhan } \\
\hline so & $83.81 \mathrm{a}$ & $73.00 a b$ & $70.25 \mathrm{a}$ & $9.53 c$ & $23.43 c$ & $7.47 \mathrm{ab}$ & $23.33 b$ & $8.63 \mathrm{~b}$ \\
\hline S1 & $83.56 \mathrm{a}$ & 72.66 bc & $69.99 \mathrm{a}$ & $10.23 b$ & $23.67 c$ & $7.37 b$ & $14.33 c$ & $7.33 \mathrm{~b}$ \\
\hline S2 & $83.62 \mathrm{a}$ & $72.29 \mathrm{c}$ & $68.29 b$ & $10.40 \mathrm{a}$ & $24.90 \mathrm{~b}$ & $7.57 \mathrm{a}$ & $32.00 \mathrm{a}$ & $18.17 \mathrm{a}$ \\
\hline S3 & $83.71 \mathrm{a}$ & $73.14 \mathrm{a}$ & 70.48 a & $9.23 \mathrm{~d}$ & $25.97 \mathrm{a}$ & $7.40 a b$ & $18.67 b c$ & $7.70 \mathrm{~b}$ \\
\hline mean & $83.67^{*}$ & $72.77^{*}$ & $69.75^{*}$ & $9.85^{*}$ & $24.49^{*}$ & $7.45^{*}$ & $22.08^{*}$ & $10.46^{*}$ \\
\hline \multicolumn{9}{|l|}{ Nongxiang 18} \\
\hline so & $81.97 \mathrm{a}$ & $68.40 \mathrm{~b}$ & $64.43 \mathrm{~b}$ & $8.43 d$ & $19.20 \mathrm{a}$ & $6.60 \mathrm{a}$ & $4.33 \mathrm{~b}$ & $1.30 \mathrm{~b}$ \\
\hline S1 & $82.43 \mathrm{a}$ & $69.21 \mathrm{ab}$ & $64.29 b$ & $9.17 \mathrm{a}$ & $18.23 \mathrm{a}$ & $6.60 \mathrm{a}$ & $2.33 c$ & $0.71 \mathrm{c}$ \\
\hline S2 & $81.64 \mathrm{a}$ & $68.58 \mathrm{~b}$ & $64.57 \mathrm{~b}$ & $8.97 b$ & $18.50 \mathrm{a}$ & $6.63 a$ & $13.67 \mathrm{a}$ & $3.00 \mathrm{a}$ \\
\hline S3 & $82.52 \mathrm{a}$ & $69.77 \mathrm{a}$ & 66.39 a & $8.60 \mathrm{c}$ & $18.50 \mathrm{a}$ & $6.53 \mathrm{a}$ & $2.33 c$ & $0.73 c$ \\
\hline mean & 82.14 & 68.99 & 64.92 & 8.79 & 18.61 & 6.59 & 5.67 & 1.44 \\
\hline
\end{tabular}

Means in the same column followed by different lower case letters for the same variety differ significantly at $P=0.05$ by LSD tests. Means of the two varieties followed by asterisk for the same grain quality trait difer significant at $P=0.05$ by LSD tests.

none for Nongxiang 18. No correlation was found between total nitrogen and GABA, proline or 2-AP and between proline and total nitrogen, GABA or 2-AP in either variety (Table 3).

\section{Effect of shading treatment on the relative content (\%) volatile compounds}

Eleven volatile compounds were measured: (E)-2Hexenal, 1-Hexanol, Heptanal, 2-acetyl-1-pyrroline, Octane, 1-Heptanol,1-Octen-3-ol, Octanal, Benzyl alcohol, Benzeneacetaldehyde, and 3,8-Dimethylundecane. For Yuxiangyouzhan, shading treatments significantly increased relative content in (E)-2-Hexenal. S3 significantly increased relative content in 2 -AP. Shading treatments (S2 and S3) significantly decreased relative content in Octane. S1 treatment significantly increased the relative content of Octanal and Benzyl alcohol. For Nongxiang 18, shading treatments (S2 and S3) significantly increased the

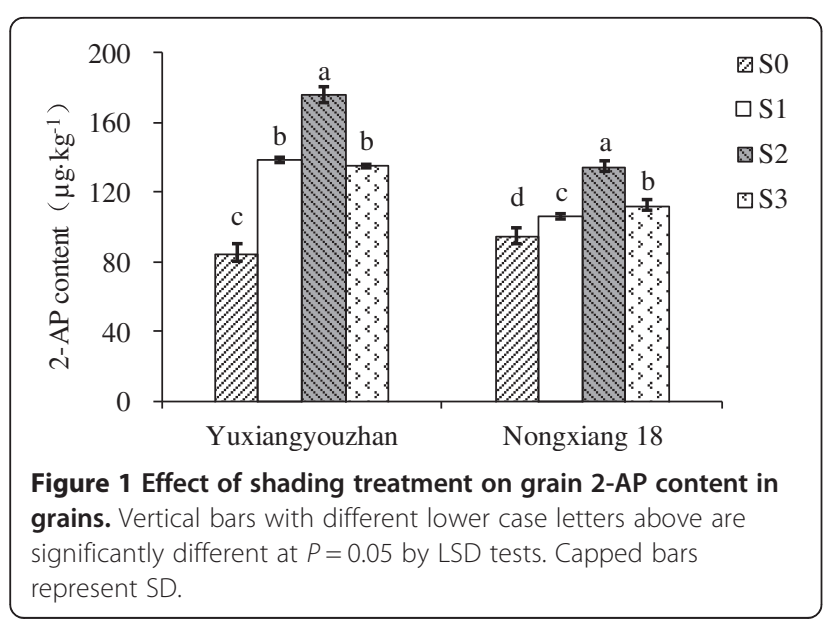

relative content of (E)-2-Hexenal. Shading treatments significantly increased the relative content of 2-AP. S3 significantly decreased the relative content of Octane, while significantly increased the relative content of Octanal. Shading treatment (S1 and S3) significantly increased the relative content of Benzyl alcohol. Shading treatments (S1and S2) significantly increased the relative content of 3,8-Dimethylundecane. As for the comparision between the two varieties, Yuxiangyouzhan had a significant higher relative content of 2-AP than Nongxiang 18. The relative content of (E)-2-Hexenal, Heptanal, Octane, and Octanal in Nongxiang 18 was significantly higher than that of Yuxiangyouzhan (Table 4).

\section{Discussion}

Shading limits photosynthetically active radiation (PAR) and can be a source of plant stress. Several studies have assessed the effect of shading on growth and yield in

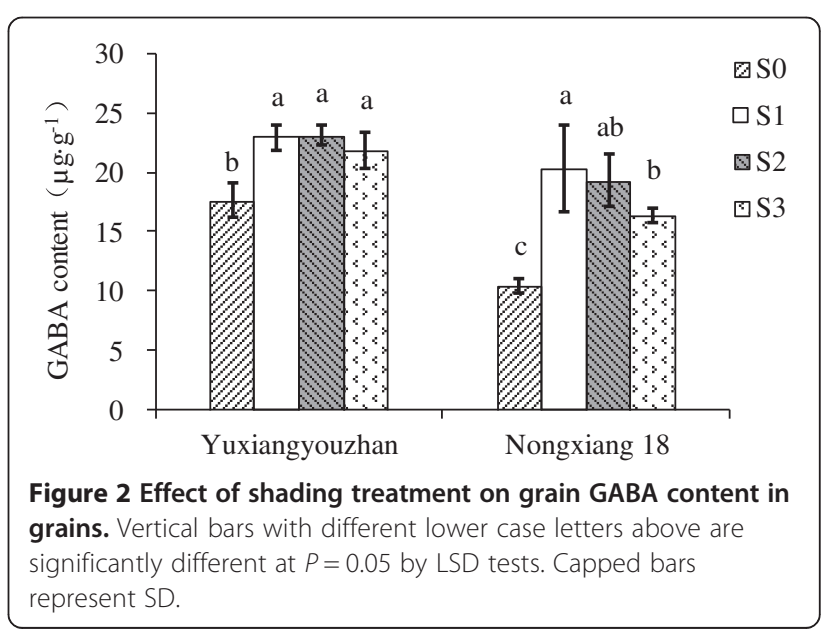




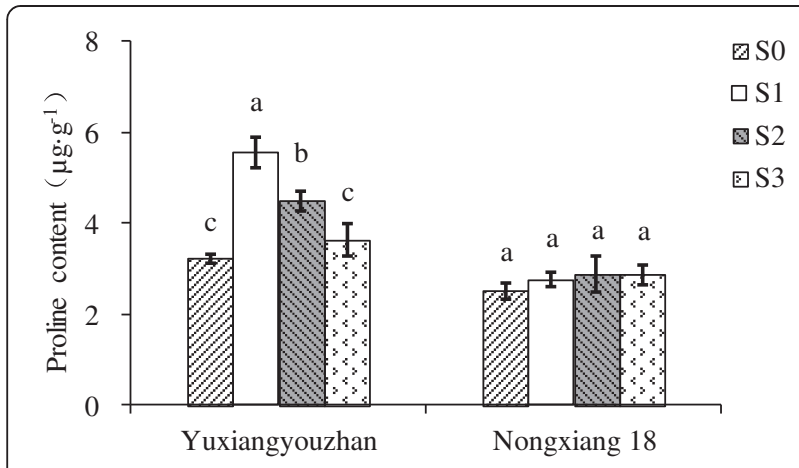

Figure 3 Effect of shading treatment on proline content in grains. Vertical bars with different lower case letters above are significantly different at $P=0.05$ by LSD tests. Capped bars represent SD.

cereal crops including rice; shading during flowering and grain development has been consistently found to decrease yield (e.g. Beed et al., 2007; Zhang et al., 2006; Liu and Tollenaar, 2009; Deng et al., 2009). Zhang et al. (2007) found that shading affects quality traits in rice, and generally, shading resulted in increased grain protein content and decreased amylose content, as well as an increased rate of chalky rice grains and a greater average degree of chalkinesss. In this study, during the whole (S1), early (S2), or late (S3) grain filling period, shading treatment resulted in significantly decreased yield in two elite Chinese fragrant rice varieties, with S1 treatment resulting in the greatest yield losses. Yield losses were more substantial in Yuxiangyouzhan than Nongxiang 18 under all shading treatments; this is consistent with previous studies in which genotype has been found to influence yield loss due to shading in rice (Zhu et al., 2008; Deng et al., 2009). Shading treatment also significantly affected quality traits. An increase in grain protein content under all treatments and a consistent effect of treatment on grain chalkiness were observed for both varieties. Significant shading effects were also identified for most other quality traits assessed, however

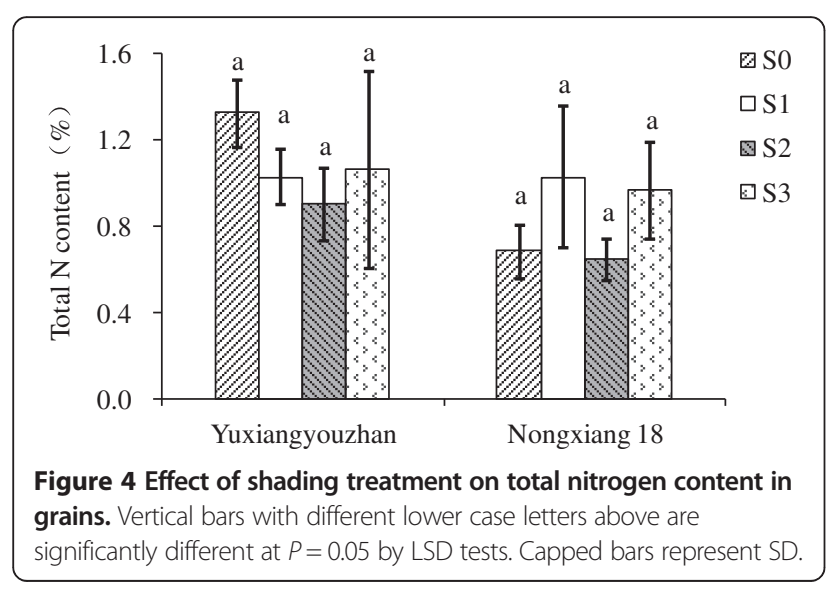

these varied with timing, duration of treatment, and cultivar. Together, these results are largely consistent with previous literature and confirm that shading during grain development can have a substantial effect on grain yield and quality in fragrant rice.

Here we have found that all shading treatments significantly increased the concentration of both 2-AP and GABA in the grain of Yuxiangyouzhan than Nongxiang 18 ; furthermore, positive correlation between the accumulation of these compounds was observed in both varieties. Although GABA has been shown to accumulate in response to a range of stresses, direct assessment of the impact of shade on GABA accumulation appears limited; our results demonstrate that the conserved response of GABA to plant stress extends to shading in rice. Furthermore, our results indicate that the association between plant stress and accumulation of 2-AP exists for shading in addition to drought and salt. We also assessed accumulation of proline in reponse to shading treatment. This was significantly increased in Yuxiangyouzhan by S1 and S2 treatment; in contrast, no significant effect was detected for any shading treatment in Nongxiang 18. This suggests that there may be substantial variation of proline accumulation in response to shading in fragrant rice varieties.

Our observations of the accumulation of GABA and 2-AP in response to shading draw attention to the hypothesized relationship of the biochemistry of these compounds in fragrant rice. As outlined above, in vitro rice $\mathrm{BADH} 2$ catalyses the conversion of GABald to GABA, a molecule that has been widely implicated in plant stress responses (Bouche and Fromm, 2004; Kinnersley and Turano, 2000) and it has been hypothesized that in fragrant rice non-functional $B A D H 2$ leads to the accumulation of GABald, which cyclises and reacts with acetyl group forming 2-AP (Bradbury et al., 2008). However, although GABA can be synthesized in plants via GABald, the primary pathway for GABA production is thought to be the 'GABA shunt', in which glutamate is converted to GABA via glutamate decarboxylase (GAD) (Fait et al., 2008).

If 2-AP indeed accumulates in fragrant rice via a pathway that produces GABA from GABald in the presence of functional $B A D H 2$ (Bradbury et al., 2008), it is intriguing that the accumulation of both GABA and 2-AP increases in response to shade. This suggests that there may be parallel activation of pathways leading to GABA in response to shading in fragrant rice, with 2-AP accumulating from GABald rather than GABA due to nonfunctional $B A D H 2$, but GABA also accumulating via the GABA shunt. However, it is possible that the accumulation of both GABA and 2-AP occurs via GABald. If another enzyme exists in rice that catalyses the conversion of GABald to GABA, non-functional BADH2 may result 
Table 3 Correlation coefficients among 2-AP, GABA, total nitrogen, and proline content in grains

\begin{tabular}{|c|c|c|c|c|}
\hline Index & 2-AP content & Grain GABA content & Proline content & Total nitrogen content \\
\hline \multicolumn{5}{|l|}{ Yuxiangyouzhan } \\
\hline 2-AP content & 1 & $0.8326^{* *}$ & 0.5460 & -0.5557 \\
\hline GABA content & $0.8326^{* *}$ & 1 & 0.6926 & -0.3402 \\
\hline Proline content & 0.5460 & 0.6926 & 1 & -0.2272 \\
\hline Total nitrogen content & -0.5557 & -0.3402 & -0.2272 & 1 \\
\hline \multicolumn{5}{|l|}{ Nongxiang 18} \\
\hline 2-AP content & 1 & 0.5442 & 0.5356 & -0.1758 \\
\hline GABA content & 0.5442 & 1 & 0.3565 & 0.3836 \\
\hline Proline content & 0.5356 & 0.3565 & 1 & 0.3267 \\
\hline Total nitrogen content & -0.1758 & 0.3836 & 0.3267 & 1 \\
\hline
\end{tabular}

Significant correlations at ${ }^{* *} p<0.01$.

in a loss of efficiency rather than elimination of GABA accumulation via GABald, with excess GABald leading to accumulation of 2-AP. Bradbury et al., (2008) demonstrated that BADH1, an enzyme with $~ 76 \%$ identity to BADH2, catalyses the formation of GABA from GABald in vitro, albeit at lower efficiency than BADH2. Furthermore, Singh et al., (2010) identified an association of SNPs predicted to decrease activity of BADH1 on GABald with 2-AP-based aroma strength in rice. Thus, this latter possibility seems plausible. In either case, modulation of GABA accumulation in response to stress seems a credible explanation for the decrease in stress tolerance reported to be associated with fragrance in rice (Fitzgerald et al., 2010; Wijerathna et al., 2014).

For the other volatile compounds in grains, Buttery et al. (1988) demonstrated ten probable key contributors to cooked rice aroma among the detected compounds. Two of the ten volatile compounds, 2-acetyl-l-pyrroline and Octanal have been studied extensively (e.g. Mahatheeranont et al., 2001; Jezussek et al., 2002; Wongpornchai et al., 2003; Laohakunjit and Noomhorm, 2004; Yang et al., 2008; Maraval et al., 2008; Tananuwong and Lertsiri, 2010; Goufo et al., 2011; Goufo et al., 2010; Bryant and McClung, 2010; Mathure et al., 2014; Mahattanatawee and Rouseff, 2014; Liyanaarachchi et al., 2014). In our study, 2-AP had the highest average relative content among the detected compounds in Yuxiangyouzhan, while was the the third most abundant volatile detected in Nongxiang 18. Octanal had the second higher average relative content among the detected compounds in both varieties. There was a significant difference in the average average relative content of the two compounds between the two varieties. All shading treatment significantly increased the relative content in 2-AP in Nongxiang 18, while S3 had a significant impact on relative content in 2-AP in Yuxiangyouzhan. S1 significantly increased the relative content of octanal in both varieties. Of the compounds that were posited to contribute to fragrance

Table 4 Effect of shading treatment on the relative content (\%) volatile compounds in grains

\begin{tabular}{|c|c|c|c|c|c|c|c|c|c|c|}
\hline \multirow[t]{2}{*}{ Compounds } & \multicolumn{5}{|c|}{ Yuxiangyouzhan } & \multicolumn{5}{|c|}{ Nongxiang 18} \\
\hline & So & S1 & S2 & S3 & Mean & So & S1 & S2 & S3 & Mean \\
\hline (E)-2-Hexenal & $0.58 c$ & $1.76 a$ & $1.67 a$ & $1.17 b$ & 1.29 & $1.15 b$ & $2.16 a$ & $1.86 \mathrm{a}$ & $1.55 a b$ & $1.68^{*}$ \\
\hline 1-Hexanol & $1.45 \mathrm{a}$ & $1.12 \mathrm{a}$ & $1.65 a$ & $1.69 a$ & 1.48 & $2.10 a b$ & $2.55 a$ & $2.21 \mathrm{ab}$ & $1.78 b$ & 2.16 \\
\hline Heptanal & $15.73 a$ & $19.84 a$ & 17.97a & $16.28 \mathrm{a}$ & 17.45 & $25.11 \mathrm{ab}$ & $22.99 b$ & $24.14 a b$ & $25.91 a$ & $24.51^{*}$ \\
\hline 2-acetyl-1-pyrroline & $18.06 b$ & $18.07 b$ & $18.08 b$ & $22.93 a$ & $19.29 *$ & $10.84 b$ & $14.22 \mathrm{a}$ & $14.17 a$ & $13.11 \mathrm{a}$ & 13.08 \\
\hline Octane & $7.26 a$ & $7.22 \mathrm{a}$ & $5.91 b$ & $5.83 b$ & 6.55 & 7.00ab & $7.47 a$ & $6.25 b c$ & $6.01 c$ & $6.68^{*}$ \\
\hline 1-Heptanol & $1.29 a$ & $1.07 a$ & $0.85 a$ & $0.86 a$ & 1.02 & $1.06 a$ & $0.98 a$ & $1.29 a$ & $1.02 \mathrm{a}$ & 1.09 \\
\hline 1-Octen-3-ol & $1.96 a$ & $2.16 a$ & $3.43 a$ & $1.80 \mathrm{a}$ & 2.34 & $2.12 a$ & $1.94 a$ & $1.87 a$ & $2.08 a$ & 2.00 \\
\hline Octanal & $11.92 b$ & $14.81 \mathrm{a}$ & $13.56 a b$ & $11.60 b$ & 12.97 & $13.36 b$ & $13.62 b$ & $13.26 b$ & $15.24 a$ & $13.87^{*}$ \\
\hline Benzyl alcohol & $0.24 b$ & $0.74 a$ & $0.38 \mathrm{ab}$ & $0.61 \mathrm{ab}$ & 0.52 & $0.20 b$ & $0.78 a$ & $0.27 b$ & $0.82 \mathrm{a}$ & 0.49 \\
\hline Benzeneacetaldehyde & $5.31 \mathrm{a}$ & $3.95 a$ & $4.00 a$ & $5.53 a$ & 4.70 & $4.16 a b$ & $4.90 a$ & $4.16 a b$ & $3.73 b$ & 4.23 \\
\hline 3,8-Dimethylundecane & $12.08 \mathrm{a}$ & $9.62 \mathrm{a}$ & $9.81 \mathrm{a}$ & $13.36 a$ & 11.22 & $9.46 b$ & $12.16 a$ & $12.22 \mathrm{a}$ & $8.67 b$ & 10.63 \\
\hline
\end{tabular}

Means in the same row followed by different lower case letters for the same variety differ significantly at $P=0.05$ by LSD tests. Means of the two varieties followed by asterisk for the same compound difer significant at $P=0.05$ by LSD tests. 
in rice by Yang et al. (2008), in addition to 2-AP and octanal, heptanal and 1-octen-3-ol were also detected in our studies; and these two compounds have also been reported in other studies (Yang et al., 2008; Tananuwong and Lertsiri, 2010; Goufo et al., 2010; Bryant and McClung, 2010; Mathure et al., 2014). We found that, heptanal had the highest average relative content in Nongxiang 18, and had the second high average relative content in Yuxiangyouzhan. Nongxiang 18 had a significant higher average relative content of heptanal than Yuxiangyouzhan. For other volatile compounds, (E)-2hexenal (Buttery et al.,1988; Yang et al., 2008; Goufo et al., 2010 , 2011), 1-hexanol (Mahatheeranont et al., 2001; Goufo et al., 2010, 2011; Mathure et al., 2014), octane (Laohakunjit and Noomhorm, 2004 ), 1-heptanol (Mahatheeranont et al., 2001; Yang et al., 2008; Goufo et al., 2010, 2011; Liyanaarachchi et al., 2014), benzyl alcohol (Wongpornchai et al., 2003; Mathure et al., 2014; Liyanaarachchi et al., 2014), benzeneacetaldehyde (Laohakunjit and Noomhorm, 2004 ), and 3,8-dimethylundecane (Mahatheeranont et al., 2001) were also detected in our study. Shading increased the relative content of (E)-2-hexenal in both varieties. There was no significant difference between shading and non-shading treatments in 1-hexanol, 1-heptanol, and benzeneacetaldehyde. Shading (S2 and S3 for Yuxiangyouzhan, S3 for Nongxiang 18) decreased the relative content of octane, and (S1 for Yuxiangyouzhan, S1 and S3 for Nongxiang 18) significantly increased the relative content of benzyl alcohol. The significant difference in 3,8-dimethylundecane was only found for Nongxiang 18 in S1 and S2 treatments. The results suggest that shading treatments may have a selective effect on the metabolism of the volatile compounds in fragrant rice.

Rice yield, grain quality and 2-AP content are key qualities for aromatic rice. In this study, we have assessed the impact of shading impact on aromatic rice yield, grain quality and 2-AP content, and some related traits. In addition to providing further insight into shading effects on crop yield and quality, and the interaction between 2-AP accumulation and stress in fragrant rice, the results of this study may have implications for rice cultivation in an environment being dramatically influenced by anthropogenic factors. Air pollution can have a shading effect, causing substantial decreases in surface level solar intensity (Jáuregui and Luyando, 1999; Qian et al., 2006), and China is well-known to experience extreme levels of air pollution (Chan and Yao, 2008) including in major agricultural regions such as the Yangtze River delta (Shao et al., 2006). There is evidence that the impact of air pollution has decreased annual solar radiation levels in Guangzhou and even the whole South China region (Liu et al., 2014). Our results suggest that high pollution levels, particularly during grain filling, could influence yield, quality and aroma in elite Chinese fragrant rice varieties. While an increased content of 2-AP as a result of the shading effect of air pollution may be desirable, yield loss and loss of grain quality would clearly be detrimental.

\section{Conclusions}

Here, we have demonstrated that shading during grain filling has significant effects on yield and quality traits in rice, and leads to the accumulation of GABA and 2-AP. These results further emphasize the important relationship between stress and 2-AP production in fragrant rice. Continuing advances in the understanding of this relationship have great potential for the optimization of both aroma production and stress resistance in elite rice varieties.

\section{Materials and methods}

\section{Plant materials and treatment conditions}

Two aromatic rice cultivars, Yuxiangyouzhan and Nongxiang 18 were used in this study. These are the main commercial fragrant rice cultivars in South China. Field experiment was carried out from July to November, 2013 at South China Agricultural University's Experimental Farm. This region has a humid subtropical monsoonal climate. The field consists of sandy, loamy soil and has been under paddy cultivation for many years. The main soil properties of the experimental site were as follows: $\mathrm{pH}, 4.88$; organic matter content, $25.65 \%$; total N, $1.362 \%$; total P, $0.958 \%$; total K, $17.520 \%$.

The experiment was arranged in split-plot design with varieties as the main plots and shading treatment as the subplots with three duplications. After years of planting, it is well-known that the duration of grain filling in the two varieties employed for this study is approximaltey 30 days. Based on previous studies, we found that a very strong shading level, corresponding to a $90 \%$ reduction in full natural light (as measured by a Luxmeter, model ZDS-10, China) resulted in a substantial increase in pest and diseases damage. Therefore, we employed a shading level equivalent to a $67 \%$ reduction of full natural light (as measured by a, Luxmeter, model ZDS-10, China) created by one layer of black netting. Four shading treatments were studied: (i) S0: the whole phase during grain filling without shading, taken as the control; (ii) S1: shading during the whole phase of grain filling (30 days, from October 3rd to November 2nd); (iii) S2: shading during the early phase of grain filling (15 days, from October 3rd to October 18th); (iv) S3: shading during the later phase of the grain filling ( 15 days, from October 18th to November 2nd). The whole grain filling stage was from the end of pollination to grain dry-down, that is from R5 to R9 in the report Counce et al. (2000), equivalent to about 30 days for the two experimental varieties. As outlined above, the whole grain filling stage was devided 
into two stages, one was the early phase of grain filling (15 days), the other was the later phase of grain filling (15 days).

The area for each subplot was $16 \mathrm{~m}^{2}$. Seeds were sown on July 15th and transplanting was performed on August 7th at a density of $20 \mathrm{~cm} \times 20 \mathrm{~cm}$ (about 400 hills per plot) with two seedlings per hill. Plants were harvested on November 5th. Fertilizer (1500 kg.ha ${ }^{-1}$; N, 12.5\%; $\mathrm{P}_{2} \mathrm{O}_{5}, 6.0 \% ; \mathrm{K}_{2} \mathrm{O}, 10.0 \%$; organic matter, $\left.15.0 \%\right)$ was applied $60 \%$ at basal, $40 \%$ at tillering stage. Irrigation, pest and diseases management, and weed control were the same in all treatments following the guidelines recommended by the province.

\section{Sampling and measurement Determination of dry weight}

Plants from ten randomly selected hills were taken to the laboratory at maturity. Plants were separated into leaves, (stem + sheath) and panicles. Sample were then oven-dried at $80^{\circ} \mathrm{C}$ to constant weight for the determination of dry weight.

\section{Determination of total nitrogen content}

Total nitrogen content in grain was determined as described by Lu (1999). Briefly, the dried samples of ground grains (about $0.3 \mathrm{~g}$ ) were digested using the $\mathrm{H}_{2} \mathrm{SO}_{4}-\mathrm{HClO}_{4}$ method. The digestion was then used to determine the total nitrogen content by the Kjeldahl method with a 2300 Kjeltec Analyzer Unit (Foss Tecator $\mathrm{AB}$, Sweden).

\section{Determination of yield and yield related traits}

At maturity, grain yield was measured from one unit sampling area $\left(1 \mathrm{~m}^{2}\right)$ within each plot, threshed manually, then sun dried (adjusted to moisture content of $~ 14 \%$ ). Plants from ten randomly selected hills from each plot were sampled to investigate yield-related traits. Panicle number per $\mathrm{m}^{2}$ was measured by counting the panicle numbers of each hill within the unit area $\left(1 \mathrm{~m}^{2}\right)$ at three different locations in each plot and the mean value was taken as the final result. Panicles were threshed manually, total number of grains and number of filled grains were counted. Five samples of 1000 grains were taken randomly from filled seeds, weighted to record 1000-grain weight. Harvest index was calculated as the ratio between grain yield and dry weight at maturity, expressed as a percentage.

\section{Determination of grain quality}

About $1 \mathrm{~kg}$ rice grain from each treatment was obtained after storage at room temperature for three months. Brown rice rate was estimated using a rice huller (Jiangsu, China). Milled rice and head rice rates were estimated using a Jingmi testing rice grader (Zhejiang, China).
Percentage of grain with chalkiness and chalkiness degree were estimated using an SDE-A light box (Guangzhou, China). Amylose content, protein content, and alkali of grains were determined using an Infratec 1241 grain analyzer (FOSS-TECATOR).

\section{Determination of proline content, GABA content and 2-AP concentration}

For determination of proline, GABA, and 2-AP, fresh sample of grains from $1 \mathrm{~m}^{2}$ area of each plot were harvested and immediately stored at $-20^{\circ} \mathrm{C}$. Duplicate measurements were taken for each sample and the mean value of the three samples per treatment was taken as the final result.

The proline content was determined according to the method described by Bates et al. (1973). Briefly, grains (about $0.3 \mathrm{~g}$ ) was homogenized in $5 \mathrm{~mL}$ of $3 \%$ sulfosalicylic acid, then cooled after heating at boiling water bath for $10 \mathrm{~min}$. Samples filtered and two $\mathrm{ml}$ of the filtrate was mixed with $3 \mathrm{~mL}$ of ninhydrin reagent $(1.25 \mathrm{~g}$ ninhydrin in $30 \mathrm{~mL}$ glacial acetic acid and $20 \mathrm{~mL} 6 \mathrm{M}$ phosphoric acid) and $2 \mathrm{~mL}$ of glacial acetic acid. The reaction mixture was then heated at boiling water bath for $30 \mathrm{~min}$ and placed in an ice bath for $20 \mathrm{~min}$ before being extracted with $4 \mathrm{ml}$ of toluene. The toluene extraction was then centrifuged at $4000 \mathrm{rpm}$ for $5 \mathrm{~min}$. The absorbance of the red chromophore in the toluene fraction was measured at $520 \mathrm{~nm}$ and the amount of proline was determined by comparison with a standard curve and expressed as $\mu \mathrm{g} \cdot \mathrm{g}^{-1}$.

GABA content in grain was determined as described by Zhao et al. (2009) and Yao et al. (2008). Briefly, grain (about $0.5 \mathrm{~g}$ ) was homogenized in $5 \mathrm{~mL}$ of $60 \%$ ethanol, treated for 4 hours in a oscillations instrument (HZS-H, China) using a frequency of 200 oscillations per minute. The supernatant was then transferred to a $5 \mathrm{ml}$ centrifuge tube and centrifuged at $8000 \mathrm{rpm}$ for $3 \mathrm{~min} .1 \mathrm{~mL}$ of supernatant was added to a $10 \mathrm{~mL}$ tube, mixed with $0.6 \mathrm{~mL} 0.2 \mathrm{~mol} \cdot \mathrm{L}^{-1}$ ( $\mathrm{pH} 9.0$ ) sodium tetraborate, two $\mathrm{mL}$ $5 \%$ toluene, and $1 \mathrm{~mL} \mathrm{7 \%}$ sodium hypochlorite, then cooled after heating at $100^{\circ} \mathrm{C}$ in a water bath for 5 minutes. The absorbance of the reaction solution was measured at $645 \mathrm{~nm}$ and the amount of GABA was determined by comparison with a standard curve and expressed as $\mu \mathrm{g} \cdot \mathrm{g}^{-1}$.

Grain samples were evaluated for 2-AP concentration by synchronization distillation and extraction method (SDE) combined with GCMS-QP 2010 Plus (Shimadzu Corporation, Japan) as described by Huang et al. (2012). Briefly, Collidine (2, 4, 6-trimethylpyridine) (Sigma, Switzerland), was used as an internal standard. $10 \mathrm{~g}$ of finely ground grain was transferred into a $500 \mathrm{~mL}$ roundbottom flask containing $145 \mathrm{~mL}$ purified water; $5 \mathrm{~mL}$ of $0.914 \mu \mathrm{g} \cdot \mathrm{mL}^{-1}$ internal standard was then added. A steam 
distillation continuous extraction head was attached to the flask, and the flask was heated at $150^{\circ} \mathrm{C}$ by an oil bath pot, ZKYY (Guangzhou, China). Attached to the other head of the steam distillation continuous extraction instrument, diethyl ether $(35 \mathrm{~mL})$ was used as the solvent in a $500 \mathrm{~mL}$ round-bottom flask, and the flask was heated at $42^{\circ} \mathrm{C}$ by a water bath pot, HH-2 (Jiangsu, China). During isolation, the steam distillation continuous extraction was maintained at $10^{\circ} \mathrm{C}$ by a cold water circulation machine, YKKY-LX-300 (Beijing, China). The isolation was performed for $35 \mathrm{~min}$. The ether extract was then dried over sodium sulfate, filtered $(0.22 \mu \mathrm{m}$ filter paper, Shimadzu, Japan), and then directly used to measure 2-AP concentrations with the GCMS-QP 2010 Plus method as described in Huang et al., (2012). The GCMSQP 2010 Plus working conditions were as followings: gas chromatograph equipped with a Restek Rxi-5 ms (Shimadzu, Japan) silica capillary column $(30 \mathrm{~m} \times 0$. $32 \mathrm{~mm} \times 0.25 \mu \mathrm{m})$. The auto injector was AOC-20i, SPL1. High purity helium gas (99.999\%, Guangzhou Gases Co., LTD, China) was the carrier gas at the flow rate of $2.0 \mathrm{~mL} \cdot \mathrm{min}^{-1}$. The temperature of the $\mathrm{GC}$ oven was $40^{\circ} \mathrm{C}(1 \mathrm{~min})$, increased at $2^{\circ} \mathrm{C} \cdot \mathrm{min}^{-1}$ to $65^{\circ} \mathrm{C}$ and held at $65^{\circ} \mathrm{C}$ for $1 \mathrm{~min}$, and then increased to $220^{\circ} \mathrm{C}$ at $10^{\circ} \mathrm{C} \cdot \mathrm{min}^{-1}$, and held at $220^{\circ} \mathrm{C}$ for $10 \mathrm{~min}$. The ion source temperature was $200^{\circ} \mathrm{C}$. Under these conditions, the retention time of 2 -AP was $7.5 \mathrm{~min}$. 2-AP content was expressed as $\mu \mathrm{g} \cdot \mathrm{kg}^{-1}$. The relative content of the aroma compounds were identified on the basis of their mass spectra by comparing the spectra with the records of the NIST library.

\section{Statistical analysis}

Analysis of variance and correlation coefficients were performed using Statistix 8 (Analytical, Tallahassee, Florida, USA). The data were analyzed by one-way analysis of variance to assess differences in yield, yield related traits, total dry weight, harvest index, grain quality, 2acetyl-1-pyrroline, GABA, proline and total nitrogen between treatments.

\section{Abbreviations \\ GABA: -aminobutyric acid; 2-AP: 2-acetyl-1-pyrroline; GABald: \\ Y-aminobutyraldehyde; PAR: Photosynthetically Active Radiation; SI: solar intensity.}

\section{Competing interests}

The authors declare no potential competing interests.

\section{Authors' contributions}

ZM, XT, WL and SP designed the experiments, ZM,WL and TLF analyzed the data, and wrote the article, FX,YT, YW and HT performed the traits investigation, ZM and MD conducted the GC-MS analysis. All authors read and approved the final manuscript.

\section{Acknowledgements}

This study was supported by National Natural Science Foundation of China (31271646), Natural Science Foundation of Guangdong Province (8151064201000017), Agricultural Research Projects of Guangdong
Province (2011AO20202001), and Agricultural Standardization Project of Guangdong Province (4100 F10003). The authors would like to thank Dr. Aryadeep Roychoudhury and Altafhusain B Nadaf for their contributions to the manuscript.

\section{Author details}

${ }^{1}$ College of Agriculture, South China Agricultural University, Guangzhou, Guangdong, 510642, China. ${ }^{2}$ Scientific Observing and Experimental Station of Crop Cultivation in South China, Ministry of Agriculture. P. R. China, Guangzhou, Guangdong 510642, China. ${ }^{3}$ Crops Research Institute, Guangdong Academy of Agricultural Sciences, Guangzhou, Guangdong 510640, China. ${ }^{4}$ CSIRO Agriculture Flagship, Queensland Bioscience Precinct, 306 Carmody Rd, St Lucia, Queensland 4067, Australia.

Received: 15 July 2014 Accepted: 8 January 2015

Published online: 10 February 2015

\section{References}

Bates LS, Waldron RP, Teare ID (1973) Rapid determination of free proline for water stress studies. Plant and Soil 39:205-208

Beed FD, Paveley ND, Sylvester-Bradley R (2007) Predictability of wheat growth and yield in light-limited conditions. J Agric Sci 145(01):63-79

Bouche N, Fromm H (2004) GABA in plants: just a metabolite? Trends Plant Sci 9 (3): $110-115$

Bradbury LMT, Fitzgerald TL, Henry RJ, Jin Q, Waters DL (2005) The gene for fragrance in rice. Plant Biotechnol J 3(3):363-370

Bradbury LM, Gillies SA, Brushett DJ, Waters DL, Henry RJ (2008) Inactivation of an aminoaldehyde dehydrogenase is responsible for fragrance in rice. Plant Mol Biol 68(4-5):439-449

Bryant RJ, McClung AM (2010) Volatile profiles of aromatic and non-aromatic rice cultivars using SPME/GC-MS. Food Chem 124(2):501-513

Buttery RG, Ling LC, Mon TR (1986) Quantitative analysis of 2-acetyl-1-pyrroline in rice. J Agric Food Chem 34(1):112-114

Buttery RG, Turnbaugh JG, Ling LC (1988) Contribution of volatiles to rice aroma. J Agric Food Chem 36(5):1006-1009

Buttery RG, Ling LC, Juliano BO, Turnbaugh JG (1983) Cooked rice aroma and 2-acetyl-1-pyrroline. J Agric Food Chem 31(4):823-826

Cai KZ, Luo SM (1999) Effect of shading on growth, development and yield formation of rice. Chinese Journal of Applied Ecology 10(2):193-196 (in Chinese)

Champagne ET (2008) Rice aroma and flavor: a literature review. Cereal Chemistry 85(4):445-454

Champagne ET, Bett-Garber KL, Thompson J, Mutters R, Grimm CC, McClung AM (2005) Effects of drain and harvest dates on rice sensory and physicochemical properties. Cereal Chemistry 82(4):369-374

Chan CK, Yao X (2008) Air pollution in mega cities in China. Atmos Environ 42(1):1-42

Counce PA, Keisling TC, Mitchell AJ (2000) A uniform, objective, and adaptive system for expressing rice development. Crop Sci 40(2):436-443

Deng F, Wang L, Yao X, Wang JJ, Ren WJ, Yang WY (2009) Effects of differentgrowing-stage shading on rice grain-filling and yield. Journal of Sichuan Agricultural University 27(3):265-269 (in Chinese)

Ding SB, Zhu BY, Wu DY, Zhang L (2004) Effect of temperature and light on senescence of flag leaf and grain-filling after rice heading. Journal of South China Normal University (Natural Science Edition) 1:117-121,128 (in Chinese)

Fait A, Fromm H, Walter D, Galili G, Fernie AR (2008) Highway or byway: the metabolic role of the GABA shunt in plants. Trends Plant Sci 13(1):14-19

Fitzgerald TL, Waters DLE, Brooks LO, Henry RJ (2010) Fragrance in rice (Oryza sativa) is associated with reduced yield under salt treatment. Environmental and Experimental Botany 68(3):292-300

Gay F, Maraval I, Roques S, Gunata Z, Boulanger R, Audebert A, Mestres C (2010) Effect of salinity on yield and 2-acetyl-1-pyrroline content in the grains of three fragrant rice cultivars (Oryza sativa L.) in Camargue (France). Field Crop Res 117(1):154-160

Gommers CM, Visser EJ, Onge KRS, Voesenek LA, Pierik R (2013) Shade tolerance: when growing tall is not an option. Trends Plant Sci 18(2):65-71

Goufo P, Duan M, Wongpornchai S, Tang X (2010) Some factors affecting the concentration of the aroma compound 2-acetyl-1-pyrroline in two fragrant rice cultivars grown in South China. Frontiers of Agriculture in China 4(1):1-9

Goufo P, Wongpornchai S, Tang X (2011) Decrease in rice aroma after application of growth regulators. Agronomy for Sustainable Development 31:349-359 
Hashemi FSG, Rafii MY, Ismail MR, Mahmud TMM, Rahim HA, Asfaliza R, Malek MA, Latif MA (2013) Biochemical, genetic and molecular advances of fragrance characteristics in rice. Crit Rev Plant Sci 32(6):445-457

Haywood J M, Bellouin N, Jones A, Boucher O, Wild M, Shine K P (2011) The roles of aerosol, water vapor and cloud in future global dimming/brightening. Journal of Geophysical Research: Atmospheres (1984-2012), 116(D20203), doi:10.1029/2011JD016000

Huang ZL, Tang XR, Wang YL, Chen MJ, Zhao ZK, Duan MY, Pan SG (2012) Effects of increasing aroma cultivation on aroma and grain yield of aromatic rice and their mechanism. Scientia Agricultura Sinica 45(6):1054-1065 (in Chinese)

Jáuregui $E$, Luyando $E$ (1999) Global radiation attenuation by air pollution and its effects on the thermal climate in Mexico City. Int J Climatol 19(6):683-694

Jezussek M, Juliano BO, Schieberle P (2002) Comparison of key aroma compounds in cooked brown rice varieties based on aroma extract dilution analyses. J Agric Food Chem 50(5):1101-1105

Kinnersley AM, Turano FJ (2000) Gamma aminobutyric acid (GABA) and plant responses to stress. Crit Rev Plant Sci 19(6):479-509

Laohakunjit N, Noomhorm A (2004) Supercritical carbon dioxide extraction of 2acetyl-1-pyrroline and volatile components from pandan leaves. Flavour and Fragrance Journal 19(3):251-259

Liu AJ, Chen WC, Qin Q (2014) An Analysis and estimation on Solar energy resources in Guangzhou city.Guangdong. Meteorology 36(3):59-61 (In Chinese)

Liu B, Han Y, Xie WX, Li JG, Liu J, Gao Q (2008) The impact of weak light during grain filling on rice yield, physiology and quality. Chinese Rice 5:36-40 (in Chinese)

Liu L, Wang L, Deng F, Huang Y, Liu DY, Ren WJ, Yang WY (2012) Osmotic regulation substance content and activities of protective enzymes in leaves of diffenent hybrid rice combinations as affected by shading. Chinese Journal of Rice Science 26(5):569-575 (in Chinese)

Liu W, Tollenaar M (2009) Response of yield heterosis to increasing plant density in maize. Crop Sci 49(5):1807-1816

Liyanaarachchi GD, Kottearachchi NS, Samarasekera R (2014) Volatile profiles of traditional aromatic rice varieties in Sri Lanka. Journal of the National Science Foundation of Sri Lanka 42(1):87-93

Lu RK (1999) Analys is measures for agro-chemical on soil. China Agricultural Science and Technology Press, Beijing, pp 1-638 (In Chinese)

Mahatheeranont S, Keawsa-ard S, Dumri K (2001) Quantification of the rice aroma compound, 2-acetyl-1-pyrroline, in uncooked Khao Dawk Mali 105 brown rice. J Agric Food Chem 49(2):773-779

Mahattanatawee K, Rouseff RL (2014) Comparison of aroma active and sulfur volatiles in three fragrant rice cultivars using GC-Olfactometry and GC-PFPD. Food Chem 154:1-6

Maraval I, Mestres C, Pernin K, Ribeyre F, Boulanger R, Guichard E, Gunata Z (2008) Odor-active compounds in cooked rice cultivars from Camargue (France) analyzed by GC-O and GC- MS. J Agric Food Chem 56(13):5291-5298

Maraval I, Sen K, Agrebi A, Menut C, Morere A, Boulanger R, Gay F, Mestresa C, Gunata Z (2010) Quantification of 2-acetyl-1-pyrroline in rice by stable isotope dilution assay through headspace solid-phase microextraction coupled to gas chromatography-tandem mass spectrometry. Anal Chim Acta 675(2):148-155

Mathure SV, Jawali N, Thengane RJ, Nadaf AB (2014) Comparative quantitative analysis of headspace volatiles and their association with $B A D H 2$ marker in non-basmati scented, basmati and non-scented rice ( Oryza sativa L.) cultivars of India. Food Chem 142:383-391

McCree KJ (1981) Photosynthetically active radiation. Physiological Plant Ecology I, Springer Berlin Heidelberg 41-55

Niu XL, Tang W, Huang WZ, Ren GJ, Wang QL, Luo D, Xiao YY, Yang SM, Wang F, Lu BR, Gao FY, Lu TG, Liu YS (2008) RNAi-directed downregulation of OsBADH2 results in aroma (2-acetyl-1-pyrroline) production in rice (Oryza sativa L.). BMC Plant Biol 8(1):100. doi:10.1186/1471-2229-8-100

Poonlaphdecha J, Maraval I, Roques S, Audebert A, Boulanger R, Bry X, Gunata Z (2012) Effect of timing and duration of salt treatment during growth of a fragrant rice variety on yield and 2-Acetyl-1-pyrroline, proline, and GABA levels. J Agric Food Chem 60(15):3824-3830

Qian Y, Kaiser DP, Leung LR, Xu M (2006) More frequent cloud-free sky and less surface solar radiation in China from 1955 to 2000. Geophys Res Lett 33(1), L01812. doi:10.1029/2005GL024586

Ren WJ, Yang WY, Fan GQ, Zhu XM, Ma ZH, Xu JW (2003) Effect of low light on dry matter accumulation and yield of rice. Journal of Sichuan Agricultural University 21(4):292-296 (in Chinese)
Sakthivel K, Sundaram RM, Shobha Rani N, Balachandran SM, Neeraja CN (2009) Genetic and molecular basis of fragrance in rice. Biotechnol Adv 27(4):468-473

Shao M, Tang XY, Zhang YH, Li WJ (2006) City clusters in China: air and surface water pollution. Front Ecol Environ 4(7):353-361

Singh A, Singh PK, Singh R, Pandit A, Mahato AK, Gupta DK, Tyagi K, Singh AK, Sharma TR (2010) SNP haplotypes of the BADH1 gene and their association with aroma in rice (Oryza sativa L.). Molecular breeding 26(2):325-338

Szabados L, Savouré A (2010) Proline: a multifunctional amino acid. Trends Plant Sci 15(2):89-97

Tanaka A, Kawano K (1966) Effect of mutual shading on dry-matter production in the tropical rice plant. Plant and Soil 24(1):128-144

Tananuwong K, Lertsiri S (2010) Changes in volatile aroma compounds of organic fragrant rice during storage under different conditions. J Sci Food Agric 90(10):1590-1596

Tang YY (1988) Effects of shading on growth, development and yieldconstituting factors of rice. Plant Physiology Communications 2:50-53 (in (hinese)

Tsugita T (1985) Aroma of cooked rice. Food Reviews International 1(3):497-520

Wang L, Deng F, Ren WJ, Yang WY (2013) Effects of Shading on starch pasting characteristics of Indica hybrid rice (Oryza sativa L.). PLoS One 8(7):e68220. doi:10.1371/journal.pone.0068220

Widjaja R, Craske JD, Wootton M (1996) Comparative studies on volatile components of non-fragrant and fragrant rices. J Sci Food Agric 70(2):151-161

Wijerathna YMAM, Kottearachchi NS, Gimhani DR, Sirisena DN (2014) Exploration of relationship between fragrant gene and growth performances of fragrant rice (Oryza sativa L.) seedlings under salinity stress. Journal of Experimental Biology and Agricultural Sciences 2(1):7-12

Wongpornchai S, Sriseadka T, Choonvisase S (2003) Identification and quantitation of the rice aroma compound, 2-acetyl-1-pyrroline, in bread flowers (Vallaris glabra Ktze). J Agric Food Chem 51(2):457-462

Yang DS, Shewfelt RL, Lee KS, Kays SJ (2008) Comparison of odor-active compounds from six distinctly different rice flavor types. J Agric Food Chem 56(8):2780-2787

Yao S, Yang TW, Zhao L, Xiong SB (2008) The variation of $\gamma$-aminobutyric acid content in germinated brown rice among different cultivars. Scientia Agricultura Sinica 41(12):3974-3982 (in Chinese)

Yoshihashi T, Kabaki N, Nguyen TTH, Inatomi H (2002) Formation of flavor compound in aromatic rice and its fluctuations with drought stress. Research Highlights JIRCAS 2003(2004):32-33

Zhang JW, Dong ST, Wang KJ, Hu CH, Liu P (2006) Effects of shading on the growth, development and grain yield of summer maize. Chinese Journal of Applied Ecology 17(4):657-662 (in Chinese)

Zhang LL, ZhangWZ, Han YD, Wang ZH, Yan LX, Gao SK (2007) Effect of shding on rice quality of diffenent panicle types.Liaoning Agricultural Science (2): 18-21 (in Chinese)

Zhao DW, Pu XY, Zeng YW, Li BX, Du J, Yang SM (2009) Determination of the $\gamma$-aminobutyric acid in barley. Journal of Triticeae Crops 29(1):69-72 (in Chinese)

Zhu P, Yang SM, Ma J, Li SX, Chen Y (2008) Effect of shading on the photosynthetic characteristics and yield at later growth stage of hybrid rice combination. Acta Agromomica Sinica 34(11):2003-2009 (in Chinese)

\section{Submit your manuscript to a SpringerOpen ${ }^{\circ}$ journal and benefit from:}

- Convenient online submission

- Rigorous peer review

- Immediate publication on acceptance

- Open access: articles freely available online

- High visibility within the field

- Retaining the copyright to your article

Submit your next manuscript at $>$ springeropen.com 